\section{Choice behavior and preexposure: A within-subjects study ${ }^{1}$}

\author{
JAMES L. PATE, Georgia State University, \\ Atlanta, Ga. 30318
}

Twenty-seven male albino rats were observed in a black-white T-maze following exposure to a black, gray, or white stimulus for either 0,45 , or 90 sec. Each rat was observed on each of 2 days under each of the nine experimental conditions. Preexposure brightness did not affect the frequency of subsequent choices. Length of exposure also had no effect on later choices. Latency, the time before the animal left the exposure box, was significantly shorter from the white box than from either the gray or the black box with the longest latency being from the black box. It was concluded that preexposure effects, if such exist, are very small.

Glanzer's (1953) stimulus satiation theory predicts that exposure to a stimulus will affect subsequent choice behavior involving that stimulus. Glanzer (1958) showed that exposure to one goal arm of a $\mathrm{T}$-maze results in an increased tendency to choose the other arm when given a free trial immediately following goal arm exposure. However, Walker, Dember, Earl, Fliege, \& Karoly (1955) found that exposure to a stimulus outside the maze resulted in no change in stimulus choice. Pate \& Anders (1967) found that relatively long exposure (10 $\mathrm{min}$ or more) to a stimulus resulted in significant selection of the nonexposed stimulus when the choice immediately followed the exposure. Additionally, Pate (1967) found that exposure results in changes in latency even when no changes in choice behavior occur. Two recent studies (Lester, 1968; Furry, Brainerd, \& Kirkpatrick, 1969) failed to find preexposure effects but, with respect to the Lester study, the outcome can be questioned (Pate, 1970). The present study is an attempt to replicate the Pate \& Anders (1967) findings with relatively brief exposure periods in a within-Ss design. \section{METHOD}

Twenty-seven male albino rats were used as Ss. All the animals had been used in a previous maze study and thus were gentle at the start of the experiment. Food and water were available ad lib. A T-maze was constructed of wood and was painted flat gray on all interior surfaces. The choice arms were $21 \times 4 \times 6$ in. A start stem measured $18 \times 2 \times 6$ in. The entire maze was covrred with hardware cloth painted flat gray. Boxes that served both as the exposure box and the startbox of the maze were 12-in. cubes painted either black, white, or gray. A guillotine-type door separated the exposure box from the start stem. The goal arms were constructed so that cardboard inserts could be placed in each arm to make the arm either black or white.

On each trial the $E$ placed the rat in the exposure box and at the end of the exposure period opened the door to the start stem. Start latency and running time were measured with a hand-operated stopwatch. Latency was the time from the opening of the door until the animal had placed all four feet in the start stem. Running time was the time from the entrance into the start stem until the animal had placed all four feet in one of the goal arms. The choice on each trial was recorded also. Three exposure periods $(0$, 45 , and $90 \mathrm{sec}$ ) were used. Each rat was exposed twice at each exposure interval to each of the three brightnesses. For each exposure brightness and time, the black arm was on the left for one exposure and on the right for the other exposure. Each rat was given a single trial on each of 18 consecutive days with a different random order being used for each animal.

\section{RESULTS}

Table 1 shows the number of times the animals chose black for each exposure period and each exposure brightness. The maximum score in each cell would be 54 since each animal was observed twice under each condition. For each condition the frequency of choice of the nonexposed arm does not differ from chance if it is assumed that there is no brightness preference. Exposure to white resulted in a slight increase in the frequency of black choices, but exposure to black resulted in an even greater increase in black choices. The frequency of choice of the nonexposed arm of the maze was

Table 1

Number of Times the Animals Chose Black

\begin{tabular}{rrrrr}
\hline & \multicolumn{4}{c}{ Exposure } \\
\multicolumn{2}{c}{ Exposure } & \multicolumn{3}{c}{ Box Brightness } \\
\cline { 2 - 5 } Time & White & Gray & Black & Total \\
\hline 0 & 33 & $38^{*}$ & $41^{*}$ & 112 \\
45 & 33 & 34 & 40 & 107 \\
90 & 35 & 24 & 30 & 90 \\
Total & 101 & 96 & 111 & 309 \\
\hline
\end{tabular}

* For each cell, except the two marked with an asterisk, the number of observations was 54. For the Gray cell, there were 53 observations and for the Black cell there were 55 observations, due to an error in assigning $S$ s to conditions. converted to an arc sin of the percent of choice and analyzed in a Subjects by Exposure analysis of variance. Exposure had no effect on subsequent choices ( $F=2.198, \mathrm{df}=2 / 52$, n.s. $)$.

As Pate (1967) showed, exposure may affect latency even when the frequency of choice is not affected. The mean running time and latency following exposure to each brightness was computed and analyzed with Friedman's rank analysis of variance. Mean running time did not differ as a function of exposure brightness. Mean latency was shortest following white exposure and longest following black exposure $\left(\chi^{2}=10.1, \mathrm{p}<.01\right)$ DISCUSSION

Although Glanzer's (1953) theory clearly predicts that exposure to a stimulus should have some effect on subsequent choices regardless of the locus of the exposure, it now appears that exposure to visual stimuli outside the maze has little or no effect on choices. Pate \& Anders (1967) found a significant effect, but if one additional animal that was exposed to white had chosen white, the results would not have been significant. Lester (1968) has reported a failure to find any effect from preexposure on 4 experimental days. However, a reanalysis (Pate, 1970) that took into account position preferences, indicated that on 2 of the 4 days there was a significant effect. Additionally, Furry, Brainerd, \& Kirkpatrick (1969), in three separate experiments, failed to find a preexposure effect. The evidence, then, indicates that a preexposure effect, if it exists, is relatively small.

Although choice behavior is not affected by preexposure, there are temporal variables which show some effect. In the present study, it was found that animals exposed to white left the exposure box more quickly than animals exposed to black or gray. This supports the finding from two earlier experiments (Pate, 1967) in which the latency from a white exposure box was significantly shorter than that from a black box. It is thus possible that the effects of preexposure are too subtle to be detected by the rather gross measure of choice frequency. Temporal measures are more sensitive to such effects. It would seem advisable to measure latency and perhaps running time in future studies of exposure effects and alternation behavior.

\section{REFERENCES}

FURRY, C. A., BRAINERD, E. G., \& KIRKPATRICK, D. R. Stimulus satiation as a function of time: Partial replications. Psychological Reports, 1969, 28, 450.

GLANZER, M. Stimulus satiation: An explanation of spontaneous alternation and related phenomena. Psychological Review, $1953,60,257-268$.

GLANZER, M. Stimulus satiation in situations 
without choice. Journal of Comparative \& Physiological Psychology, 1958, 51, 332-335.

LESTER, D. Pre-exposure and stimulus choice: Effects of locale. Psychonomic Science, 1968, 12, 3-4.

PATE, J. L. Choice behavior as a function of stimulus exposure. Psychological Reports, 1967, 21, 213-219.

PATE, J. L. Preexposure and locale: Comment on Lester. Psychonomic Science, 1970, 00, $000-000$.

PATE, J. L., \& ANDERS, T. R. Extra-maze pre-exposure and choice behavior. Psychonomic Science, 1967, 7, 301-302.

WALKER, E. L., DEMBER, W. N., EARL, R. W., FLIEGE, S. E., \& KAROLY, K. J. Choice alternation: II. Exposure to stimulus and stimulus and place without choice. Journal of Comparative \& Physiological Psychology, $1955,48,24-28$.

\section{NOTE}

1. The author thanks Judy DeLoache, who collected the data for this study, for her assistance.

\section{Effect of atropine dose level on the suppression of water-reinforced VI responding}

\author{
GARTH HINES, ANDREW E. LEE, and WILLIAM T. MILLER \\ University of Montana, Missoula, Mont. 59801
}

Rats trained to barpress on a VI 1-min schedule for water reinforcement received four dose levels $(1.0,2.0,4.0$, and $8.0 \mathrm{mg} / \mathrm{kg})$ of atropine sulfate or atropine methyl nitrate. Compared with saline-injected controls, increasing doses of atropine sulfate resulted in increasing degrees of response suppression. The same result was obtained with atropine methyl nitrate, although to a lesser degree. It was suggested that the failure to obtain extensive response facilitation at the lower dose levels of atropine methyl nitrate may have been due to the existence of a limit to the operating capacity of the central thirst system.

Fisher \& Coury (1962) have suggested that there is a "medially oriented, generalized Papez circuit"-cholinergic in nature-which acts in the regulation of drinking behavior. Further, the evidence suggests that this system is specifically muscarinic (Stein \& Seifter, 1962; Levitt, 1969).

However, it has been found that the application of atropine (an antimuscarinic agent) to individual members of the system will not appreciably suppress deprivation-induced drinking, even though it will suppress drinking induced by the application of a cholinomimetic agent to other members of the system (Levitt \& Fisher, 1966, 1967). This has led to the suggestion that input from peripheral mechanisms (such as afferents from the mouth and throat, osmoreceptors, etc.) may allow the system to operate even though one or more of the components are partially blocked.

Results following the peripheral administration of atropine have suggested that the suppression of thirst-related behavior is a function of the dose level of the antimuscarinic agent given. Willis \& Windland (1968) found that $20 \mathrm{mg} / \mathrm{kg}$ atropine consistently decreased water-reinforced responding on the VI component of a multiple schedule. Stein (1963) found extensive suppression of drinking following the administration of atropine at $5 \mathrm{mg} / \mathrm{kg}$, while drinking was not significantly suppressed following the administration of $2.5 \mathrm{mg} / \mathrm{kg}$ atropine. Finally, the administration of $2 \mathrm{mg} / \mathrm{kg}$ atropine failed to affect water-reinforced VI responding (Hines, Miller, \& Lee, 1969), in spite of the fact that this dose has been shown to be centrally active in learning situations (Whitehouse, 1967). Again, peripheral feedback (here augmented by the peripheral consequences of cholinergic attenuation) has been suggested as the mechanism whereby the system is driven in spite of its partial blockage by antimuscarinic agents.

The present study was designed to further investigate the dose-response relationship between atropine sulfate (and atropine methyl nitrate) and suppression of water-reinforced VI responding. SUBJECTS

Twelve male Holtzman albino rats, 90-120 days old, were divided randomly into three equal groups and maintained at $80 \%$ of their estimated growth curve by timed access to water at the end of each day's session. In no case was more than 15-min access to water required to maintain this deprivation schedule. All Ss were housed in individual home cages.

$$
\text { APPARATUS }
$$

The Ss were tested in two rat chambers $13 \mathrm{in.}$ long $\times 10 \mathrm{in}$. high $\times 10$ in. wide. The lever was constructed of 3/8-in.-diam stainless steel rod, protruding $3 / 4$ in. in to the chamber. The grid floor was designed according to the specifications given by Dinsmoor (1958).

Each chamber was housed in a sound-insulated ventilated chest. Water reinforcements $(.02 \mathrm{ml}, 3-\mathrm{sec}$ presentation) were delivered by a Lehigh Valley Model 1351 liquid dipper. Electronic programming and recording equipment was activated by a $12-\mathrm{g}$ force on each bar.

\section{PROCEDURE}

All Ss were trained to barpress on a constant-probability VI 1-min schedule for water reinforcement. Each $S$ was tested during one $36-\mathrm{min}$ period per day, to a criterion of either 5 consecutive days, where the daily total responses fell within $\pm 15 \%$ of the mean response total for the 